\title{
Pattern of Mandibular Fracture at Universal College of Medical Sciences (UCMS), Bhairahawa, Rupandehi, Nepal
}

\author{
Shashank Tripathi ${ }^{1 *}$, Ravish Mishra ${ }^{1}$, Deepak Yadav ${ }^{1}$, Laxmi Kandel ${ }^{1}$, Bikash Pahari ${ }^{1}$ and Pradip Chhetri ${ }^{2}$ \\ ${ }^{1}$ Department of Oral and Maxillofacial Surgery, Universal College of Medical Sciences, Nepal \\ ${ }^{2}$ Department of Community Medicine, Universal College of Medical Sciences, Nepal
}

*Corresponding author: Shashank Tripathi, Lecturer, Department of Oral and Maxillofacial Surgery, UCMS College of Dental Surgery, Bhairahawa, Rupandehi, Nepal

\begin{abstract}
A descriptive retrospective study was carried out and evaluated the pattern of mandibular fractures in western region of Nepal at Universal College of Medical Sciences, Bhairahawa, Rupandehi. Among 498 cases of maxillofacial trauma registered between March 2014 to December 2018; 199 cases of mandibular fractures who were admitted and undergone conservative or surgical treatment were enrolled in the study. Parameters recorded were personal details of patients including age, sex, day and month of fracture, mode of trauma, alcohol abuse, site of mandibular fracture, treatment done, duration of hospital stay, and need for intensive care unit (ICU) stay. The selected group include 157 males $(78.9 \%)$ and 42 females $(21.1 \%)$. The mean age of patient was $30.34 \pm 13.98$ years (age range, 3-77 years). The mode of trauma was from road traffic accident (69.8\%) in majority of cases followed by physical assault (15.6\%) and fall from height (12.6\%). Majority of trauma for mandibular fracture were seen on Wednesday and Friday in the month of June followed by February and December. $27.1 \%$ of patients with mandibular fractures were under the influence of alcohol. Majority of patients (94\%) were secondarily managed with open reduction internal fixation (ORIF) under general anesthesia followed by closed reduction under local anesthesia (3\%) and circum-mandibular wiring under general anesthesia (3\%). Circum-mandibular wiring was opted for patient who were in mixed dentition period. The mean duration of hospital stay was $8.72 \pm 2.91$ days (range, 5-20 days) in which maximum hospital stays were with patients associated with craniofacial fracture and associated intracranial injury. Majority of patients (98\%) were managed post operatively in general surgical wards whereas few patients $(2 \%)$ were shifted to ICU from major operating room due to post-operative anesthetic complications. Para symphysis fracture were seen in majority of cases followed by angle and condyle respectively. The mechanism of injury correlates significantly with the anatomic location of fracture and knowledge of these associations should guide the surgeons for appropriate and timely management. Because RTAs are most frequent, good traffic sense needs to be imbibed and developed by the government as well as the public.
\end{abstract}

Keywords: Mandibular Fractures; Trauma; Pattern; RTAs

\section{Introduction}

Mandible is one of the strongest and largest bone of face. Though nasal bone is most common bone to get fractured; mandible remains the second one [1,2]. Anatomically, mandible is ' $V$ ' or 'horseshoe' shaped which is most prominent at chin region and is mobile part of our facial skeleton. Due to its shape, anatomic position and being mobile, there is high chance of bone to get fractured. During mandibular fracture, either single or multiple anatomic sites can be involved simultaneously by the impact caused by various means. The patterns of mandibular fracture differ significantly among different study populations. Maxillofacial fractures results from the variable modes of injury such as road traffic accidents (RTA), interpersonal violence or physical assaults and fall from height $[3,4]$.

Once the patient is brought to emergency department with complex maxillofacial trauma, patient management remains a challenging task for oral and maxillofacial surgeons, demanding both skills and a high level of expertise. It has been well documented that mandibular fractures account for $36 \%$ to $59 \%$ of all maxillofacial trauma [5-7]. Most of the reported prevalence of mandibular fracture is due to a variety of contributing factors such as the age and sex of patients, environment and socio-economic status of the patient, alcohol or drug abuse as well as mode of trauma. 
The combination of more than one of these factors determines the chance of a mandibular fracture in every single patient [8].

Despite of many published reports about the incidence and pattern of mandibular fractures, there are limited literatures about the specific type or pattern of mandibular fractures related to RTA in developing and underdeveloped Asian countries. The present study aimed to determine the age group and sex in which mandibular fracture occurred most often; to determine the mode of trauma; to know the pattern of mandible fracture which involve either single or multiple sites; to know the possible contributory role of alcohol and drug abuse; to report on the modalities of treatment provided and number of days stayed in hospital or ICU.

\section{Materials and Methods}

The investigators designed and implemented a descriptive retrospective study that was approved by the Institutional Review Committee (IRC) of the Universal College of Medical Sciences, Bhairahawa, Nepal (IRC number 045/19). Among 498 cases of maxillofacial trauma registered between March 2014 to December 2018 at UCMS College of Dental Surgery, Bhairahawa, Rupandehi, Nepal; 199 cases of mandibular fractures who were admitted and undergone conservative or surgical treatment were enrolled in the study. Parameters recorded were personal details of patients including age, sex, day and month of fracture, mode of trauma, alcohol abuse, site of mandibular fracture, treatment done, duration of hospital stay, and need for intensive care unit (ICU) stay. All maxillofacial injuries excluding mandibular fractures and patients with incomplete medical record information were not included in the study.

Data were entered in Microsoft Excel 2007 and analyzed by means of Statistical Package for Social Sciences (SPSS 18.0 for Windows, SPSS Inc.). For descriptive statistics; percentage, mean, range and standard deviation were calculated.

\section{Results}

A total of 199 cases of mandibular fracture with complete medical records admitted and managed with stipulated period were included in the present study. The selected group include 157 males (78.9\%) and 42 females $(21.1 \%)$ as shown in Figure 1. The mean age of patient was $30.34 \pm 13.98$ years (age range, $3-77$ years) as shown in Table 1. The mode of trauma was from road traffic accident $(69.8 \%)$ in majority of cases followed by physical assault (15.6\%) and fall from height (12.6\%) as shown in Figure 2. Majority of trauma for mandibular fracture were seen on Wednesday and Friday in the month of June followed by February and December as shown in Figure 3 \& 4. 27.1\% of patients with mandibular fractures were under the influence of alcohol as shown in Figure 5. Majority of patients (94\%) were secondarily managed with open reduction internal fixation (ORIF) under general anesthesia followed by closed reduction under local anesthesia (3\%) and circummandibular wiring under general anesthesia (3\%) as shown in Figure 6. Circum-mandibular wiring was opted for patient who were in mixed dentition period. The mean duration of hospital stay was $8.72 \pm 2.91$ days (range, 5-20 days) in which maximum hospital stays were with patients associated with craniofacial fracture as shown in Table 1. Majority of patients (98\%) were managed post operatively in general surgical wards whereas few patients (2\%) were shifted to ICU from major operating room due to postoperative anesthetic complications as shown in Figure 7. Para symphysis fracture were seen in majority of cases followed by angle and condyle respectively as shown in Figure 8. Body of mandible fracture were least fractured.

Table 1: Mean age and duration of hospital stays of patients.

\begin{tabular}{|c|c|c|}
\hline Parameters & Mean & Std. Dev. \\
\hline Age(years) & 30.34 & 13.98 \\
\hline Hospital stay (days) & 8.72 & 2.91 \\
\hline
\end{tabular}

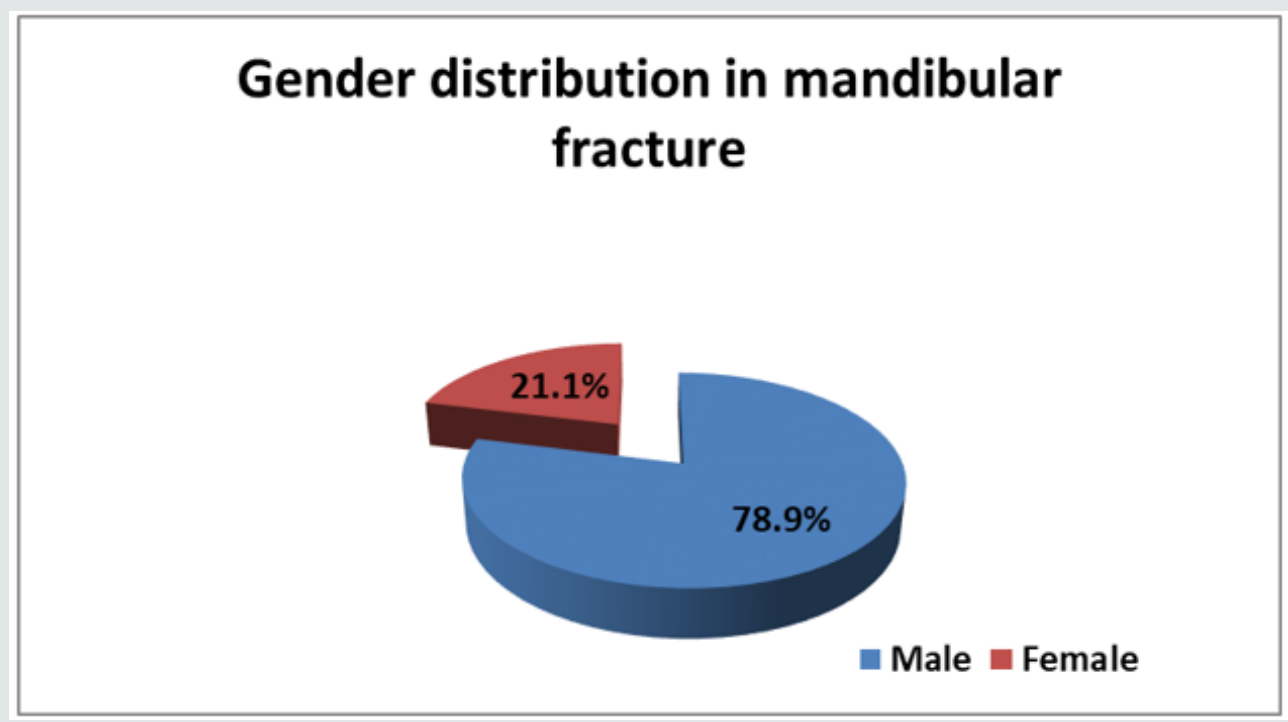

Figure 1: Gender distribution in patients of mandibular fracture. 


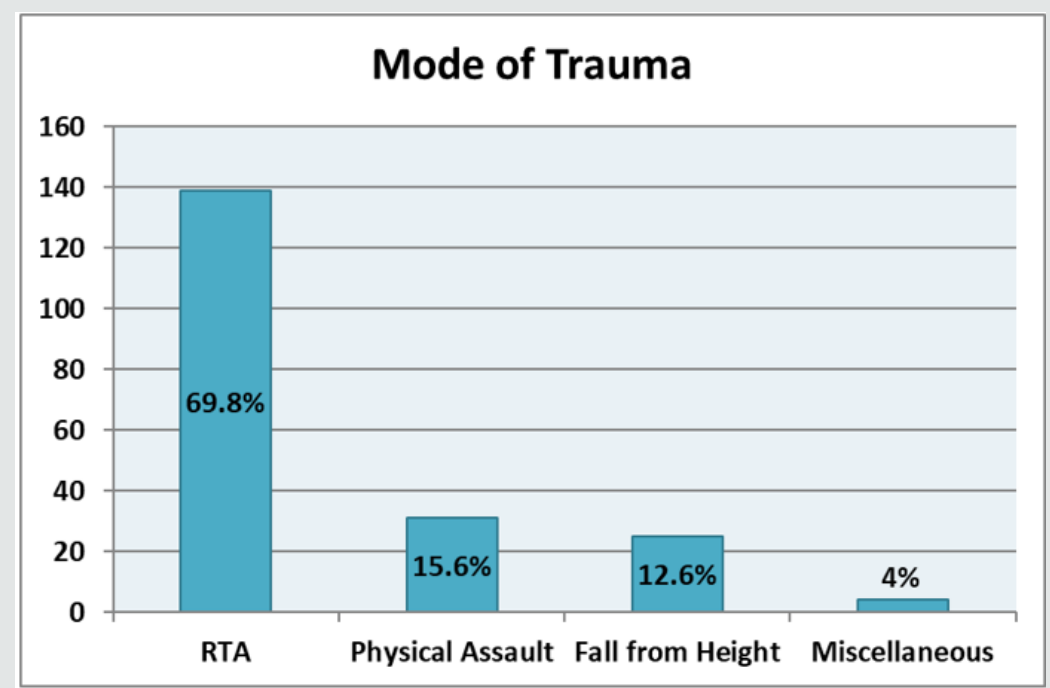

Figure 2: Mode of trauma in patients with mandibular fracture.

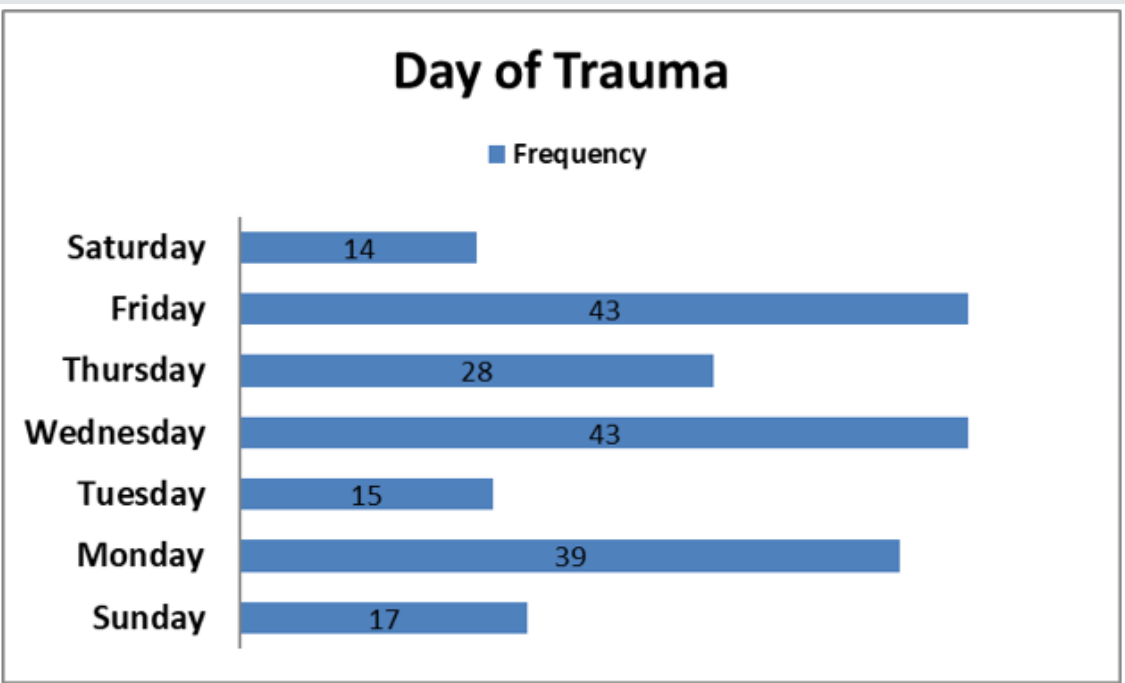

Figure 3: Day wise distribution of patients with mandibular fracture.

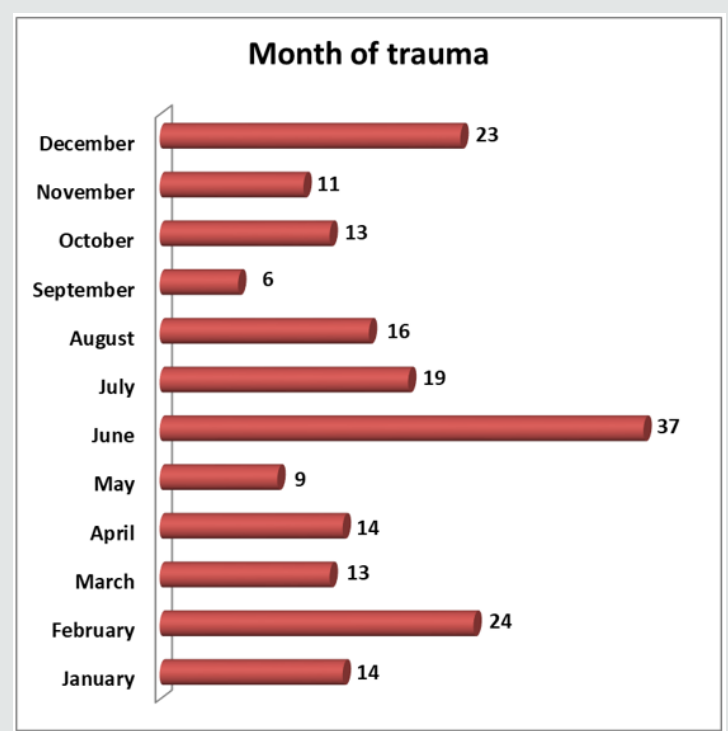

Figure 4: Month wise distribution of patients with mandibular fracture. 


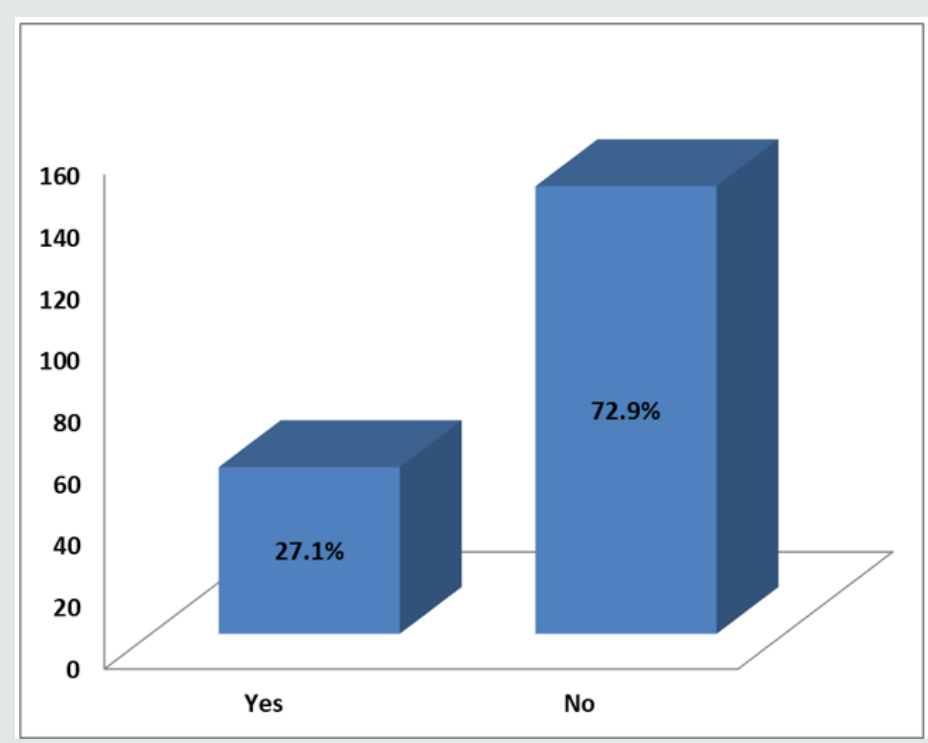

Figure 5: Influence of alcohol in patients with mandibular fracture.

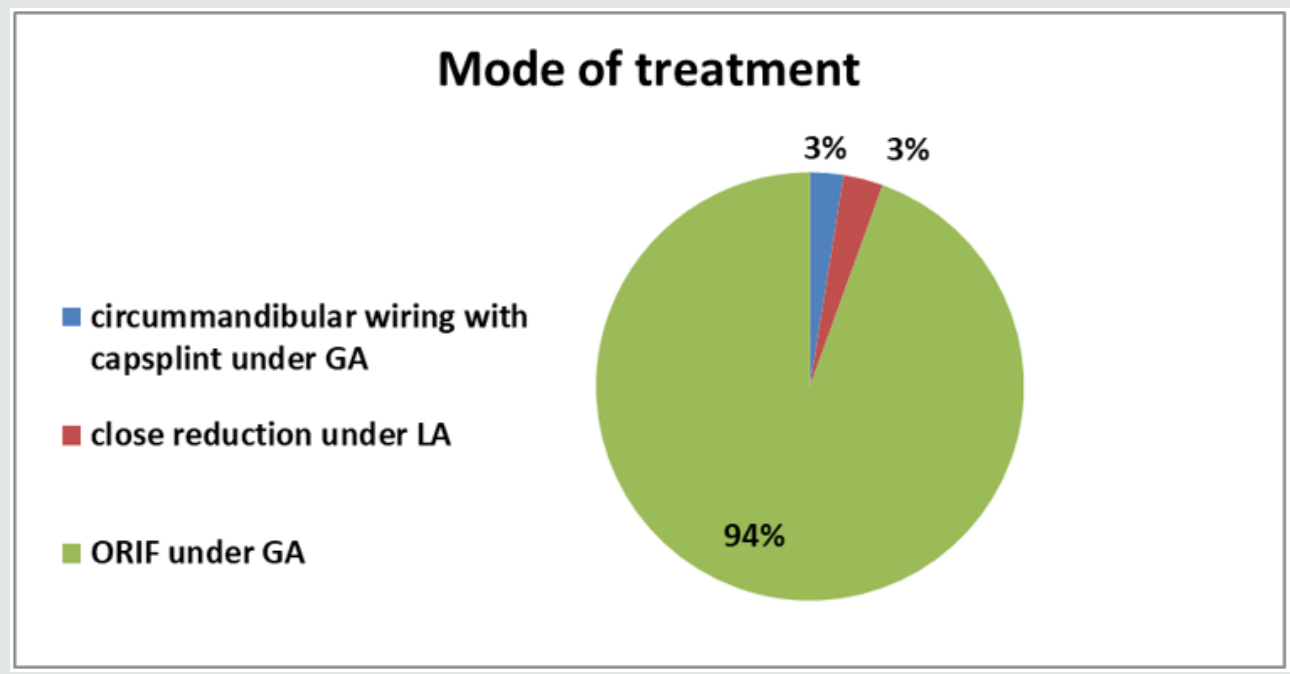

Figure 6: Mode of treatment in patients with mandibular fracture.

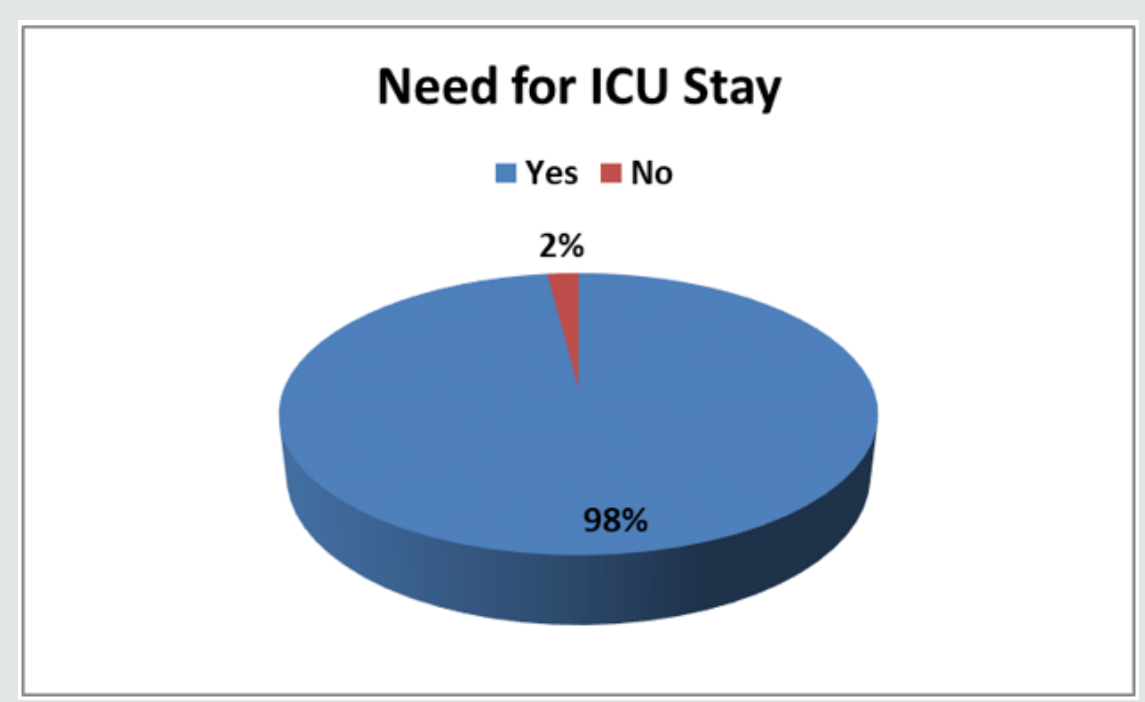

Figure 7: Need for ICU stay in patients with mandibular fracture. 


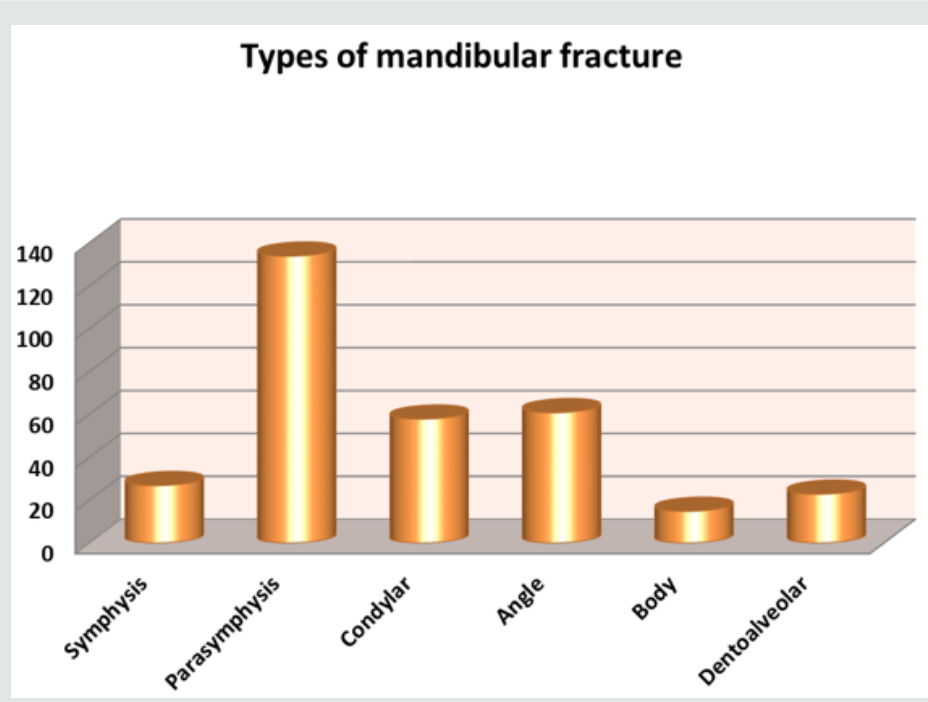

Figure 8: Individual site fracture distribution in patient with mandibular fracture.

\section{Discussion}

The present study comprised of complete medical records within stipulated time period of patients $(n=199)$ aged 3 to 77 years with mandibular fractures attending Department of Oral and Maxillofacial Surgery, UCMS College of Dental Surgery, Bhairahawa which is the only tertiary centre in western region of Nepal. Various studies had been reported worldwide regarding the prevalence and pattern of mandibular. The result of present study coincides with the study done previously irrespective of age and sex [1-11]. In present study, the mean age of patients in years is $30.34 \pm 13.98$ $[1,2,4,5,8-10]$.

Most of the patients fall between age group of 21-35 years. RTA (69.8\%) being the commonest mode of trauma in mandibular fracture followed by physical assault and fall from height. Most common reasons for this may be due to the low socioeconomic status of people leading to use of high numbers of two-wheelers like bicycles, motorbikes, etc.; lack of awareness in using safety measures in the form of helmets; use of alcohol while driving, poor road condition and hilly areas. Males were predominant than females in the present study. $78.9 \%$ of males were involved and the reason behind this may be due to male dominant and dependent society.

In the present study, Wednesday and Friday were the most common days where patients were admitted with mandibular fracture. Friday is the weekend for people in Nepal and Wednesday is the mid of week where people try to engage themselves in social gathering. In addition, alcohol is very easily available and commonly used in such occasion. So, the chance of increase in RTA and interpersonal violence under the influence of alcohol plays a significant role. Month wise distribution shows higher incidence of mandibular fracture in the month of June in the present study. In Nepal, June is the month when there is maximum rainfall due to which the condition of road is worsened and become slippery.

Para symphysis fracture was the most commonly observed mandibular fracture in the present study followed by angle fracture and condylar fracture which coincides with the study done by Vetter et al. [10] According to Dingman and Natvig classification of mandibular fractures, the anatomic pattern shows the incidence of angle involvement of $36.32 \%$, followed by the body $(21.23 \%)$ and the symphysis (17.81\%) which is in coherent with the study done by [11] Olson et al. [12], Allan et al. [13] and Hill et al. [14] In contrast, study done by Hall and Ofodile [15] showed body has the highest incidence of fractures, followed by the angle. This variability in individual site fracture distribution shows that the pattern is always multifactorial and the strongest variable with a positive association is trauma via altercation.

Most of patients (94\%) reported with mandibular fractures have been treated with open reduction and internal fixation (ORIF) under general anesthesia. Patients in mixed dentition periods were managed with circum mandibular wiring (CMW) to avoid injury to developing permanent tooth buds. Only few patients who could not afford treatment charge were successfully managed with maxillomandibular fixation (MMF) with different means wiring techniques like use of Erich's arch bar, Ivy eyelet wiring, etc.

In the present study, the mean duration of hospital stays in patients with mandibular fracture is found to be $8.72 \pm 2.91$ days. Prolonged hospital stays were for polytrauma patients with associated limb fractures, concurrent intracranial injury, chest injury, etc. Very few patients (2\%) needed intensive care unit (ICU) for associated intracranial injury along with maxillofacial fractures.

\section{Conclusion}

Nepal is one of the least developed country and high number of maxillofacial injuries have been reported in which most of them have been attributed to RTAs. The incidence of maxillofacial injuries can be drastically reduced by strict enforcement of traffic rules set by Nepal government. Strict use of safety measures during driving like proper use of seat belt, helmet and no use of alcohol help to reduce higher incidence of maxillofacial injuries. The etiology is closely associated with the anatomic location of mandibular fractures. The diagnosis, pattern of fractures, and their management should be associated with a concern for medico-legal purposes. 


\section{References}

1. Adebayo ET, Ajike OS, Adekeye EO (2003) Analysis of the pattern of maxillofacial fractures in Kaduna, Nigeria. Br J Oral Maxillofac Surg 41(6): 396-400.

2. Deogratius BK, Isaac MM, Farrid S (2006) Epidemiology and management of maxillofacial fractures treated at Muhimbili National Hospital in Dar es Salaam, Tanzania, 1998-2003. Int Dent J 56(3): 131-134.

3. Scherer M, Sullivan WG, Smith DJ, Phillips LG, Robson MC (1989) An analysis of 1423 facial fractures in 788 patients at an urban trauma center. J Trauma 29(3): 388-390.

4. Thorn JJ, Mogeltoft M, Hansen PK (1986) Incidence and aetiological pattern of jaw fractures in Greenland. Int J Oral Maxillofac Surg 15(4): 372-379.

5. Brook IM, Wood N (1983) Aetiology and incidence of facial fractures in adults. Int J Oral Surg 12(5): 293-298.

6. Ellis E $3^{\text {rd }}$, Moos KF, el-Attar A (1985) Ten years of mandibular fractures: an analysis of 2137 cases. Oral Surg Oral Med Oral Pathol 59(2): 120129.

7. van Hoof RF, Merkx CA, Stekelenbrug EC (1977) The different patterns of fractures of the facial skeleton in four European countries. Int J Oral Surg 6(1): 3-11.
8. Sojot AJ, Meisami T, Sandor GK, Clokie CM (2001) The epidemiology of mandibular fractures treated at the Toronto general hospital: A review of 246 cases. J Can Dent Assoc 67(11): 640-644.

9. Adhikari R, Karmacharya A, Malla N (2012) Pattern of mandibular fractures in western region of Nepal. Nepal Journal of Medical Sciences 1(1): 45-48.

10. Vetter JD, Topazian RG, Goldberg MH, Smith DG (1991) Facial fractures occurring in a medium-sized metropolitan area: recent trends. Int J Oral Maxillofac Surg 20(4): 214-216.

11. Dingman RO, Natvig P (1964) Surgery of facial fractures. BJS Society, Saunders, Philadelphia, PA, USA

12. Olson RA, Fonseca RJ, Zeitler DL, Osbon DB (1982) Fractures of the mandible: a review of 580 cases. J Oral Maxillofac Surg 40(1): 23-28.

13. Allan BP, Daly CG (1990) Fractures of the mandible. A 35-year retrospective study. Int J Oral Maxillofac Surg 19(5): 268-271.

14. Hill CM, Burford K, Martin A, Thomas DW (1998) A one-year review of maxillofacial sports injuries treated at an accident and emergency department. Br J Oral Maxillofac Surg 36(1): 44-47.

15. Hall SC, Ofodile FA (1991) Mandibular fractures in an American inner city: the harlem hospital center experience. J Natl Med Assoc 83(5): 421423.

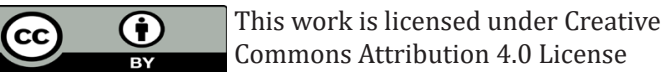

To Submit Your Article Click Here: Submit Article

DOI: $10.32474 /$ MADOHC.2019.04.000181

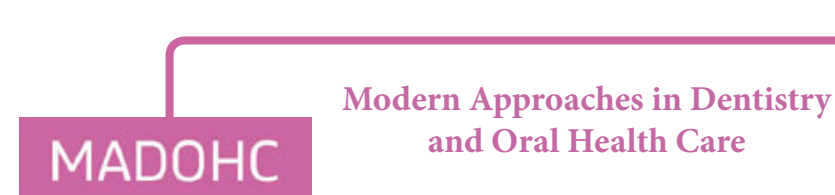

Assets of Publishing with us

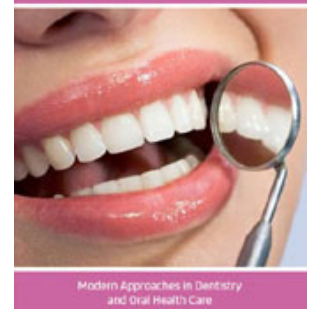

- Global archiving of articles

- Immediate, unrestricted online access

- Rigorous Peer Review Process

- Authors Retain Copyrights

- Unique DOI for all articles 